\title{
Effects of irbesartan on 24-h blood pressure changes and urinary albumin levels in Japanese outpatients
}

\author{
TADASHI ARAI ${ }^{1}$, MIHOKO SENDA $^{2}$, HITOMI YOKOYAMA $^{2}$ and KIKUKO YASUDA ${ }^{3}$ \\ ${ }^{1}$ Department of Internal Medicine, Arai Clinic, Gifu 501-2105; ${ }^{2}$ Nawa Medical Clinic, \\ Gifu 501-0311; ${ }^{3}$ Yasuda Medical Clinic, Gifu 505-0032, Japan
}

Received May 3, 2010; Accepted June 7, 2010

DOI: 10.3892/etm_00000105

\begin{abstract}
In Japan, ambulatory blood pressure monitoring (ABPM) became covered by health insurance in April 2008. In The Japanese Society of Hypertension Guidelines for the Management of Hypertension (JSH2009), the importance of 24-h blood pressure monitoring was also described in an additional section. Therefore, ABPM may be increasingly applied in hypertension treatment. However, in Japan, few studies have presented data on the effects of various anti-hypertensive agents on 24-h blood pressure changes. Irbesartan became commercially available in July 2008 as the sixth angiotensin II type 1 receptor blocker in Japan. In the present study, 24-h blood pressure control was examined using ABPM in Japanese patients with essential hypertension who were treated with irbesartan, and its efficacy was evaluated. This study was completed in 30 of the 32 subjects. This agent decreased both the nocturnal and daytime blood pressures and reduced the rate of change in the systolic blood pressure early in the morning, resulting in favorable blood pressure control. It also significantly decreased the urinary albumin level, suggesting that it exhibits renoprotective effects at doses approved in Japan.
\end{abstract}

\section{Introduction}

In clinical practice, blood pressure measurement at home is employed for non-office blood pressure monitoring, which is not possible at outpatient clinics. However, ambulatory blood pressure monitoring (ABPM), which facilitates the assessment of 24-h blood pressure changes, is necessary to measure the nocturnal blood pressure, which may be associated with organ disorders (1). In Japan, National Health Insurance coverage of ABPM began in April 2008. In The Japanese

Correspondence to: Dr Tadashi Arai, Department of Internal Medicine, Arai Clinic, 2119-1 Takatomi, Yamagata, Gifu 501-2105, Japan

E-mail: ta34718arai@cg7.so-net.ne.jp

Key words: hypertension, ambulatory blood pressure monitoring, angiotensin receptor blocker, irbesartan, urinary albumin
Society of Hypertension Guidelines for the Management of Hypertension (JSH2009) (2), the importance of 24-h blood pressure monitoring was also described as an additional section. Therefore, ABPM may be increasingly applied in hypertension treatment. However, in Japan few studies have presented data on the effects of various anti-hypertensive agents on 24-h blood pressure changes.

Irbesartan (3) became commercially available in July 2008 as the sixth angiotensin II type 1 receptor blocker (ARB) in Japan. Since this agent is characterized by a half-life of 10.2-15.4 $\mathrm{h}$ (4) and strong binding to $\mathrm{AT}_{1}$ receptors (5), it may exhibit continuous anti-hypertensive effects over $24 \mathrm{~h}$ (6). However, no data on 24-h blood pressure involving Japanese outpatients have been published. In this study, we investigated 24-h blood pressure changes in patients receiving irbesartan to evaluate its anti-hypertensive/persistent effects. In addition, we measured the urinary albumin and serum creatinine levels.

\section{Patients and methods}

Among patients newly diagnosed with hypertension in the three clinics participating in the study, those without a history of anti-hypertensive therapy within 4 weeks before the start of irbesartan administration, who were able to consult the outpatient clinic every 2 weeks and who consented to participate in this study, were registered as subjects. Physicians were prohibited from additionally administering other anti-hypertensive agents. As a rule, agents that had been prescribed (for other concomitant disorders) were not changed during the study period.

Thirty-two patients were enrolled between December 2008 and May 2009. As shown in the flow chart (Fig. 1), the criteria for registration included systolic or diastolic office blood pressure of $\geq 140 / 90 \mathrm{mmHg}$ and age ranging from 20 to 75 years, regardless of gender and complications. Patients with a urinary protein level of $\geq 100 \mathrm{mg} / \mathrm{dl}$ by urine test paper were excluded. The daily dose of irbesartan was $100 \mathrm{mg}$ (once-a-day administration); however, if necessary, the dose could be increased to $200 \mathrm{mg}$ based on the attending physician's evaluation. The blood pressure and pulse were measured along with examination for general symptoms at consultations before the start and after 2, 4 and 6 weeks of administration. A blood test and urinalysis were conducted to determine the serum creatinine 


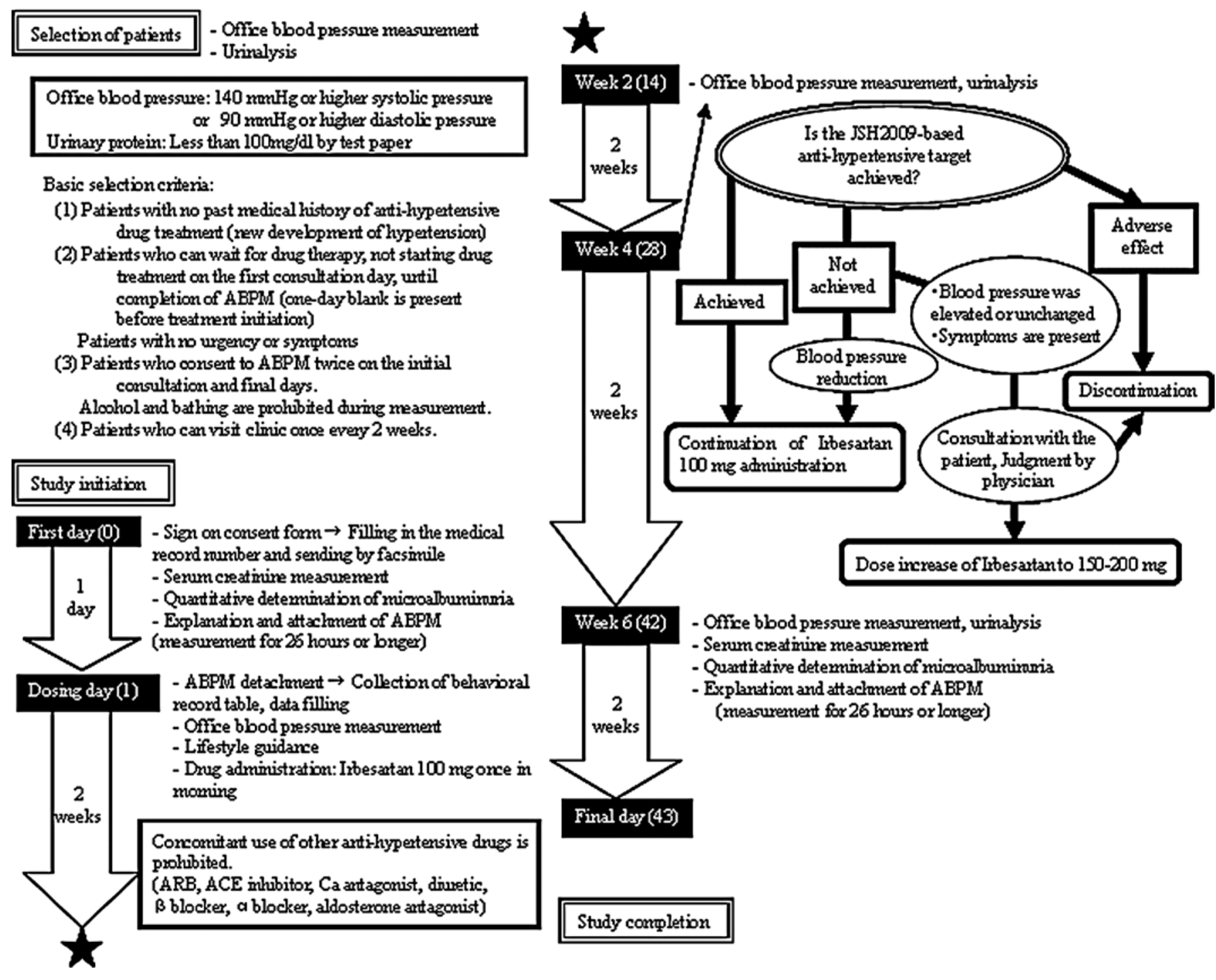

Figure 1. Treatment and study schedule.

and urinary albumin levels before and 6 weeks after the start of administration. At these points, an ABPM device was worn for $\geq 26 \mathrm{~h}$ from the time of consultation until the following day. The blood pressure was measured at 1-h intervals. For each patient, the mean of the values obtained between 9:00 pm and 5:00 am was regarded as the nocturnal blood pressure. The mean of the values obtained between 8:00 am and 6:00 pm was regarded as the daytime blood pressure. As an index of blood pressure changes early in the morning, differences in the mean blood pressure between two intervals: 3:00-5:00 am and 7:00-9:00 am were calculated. The estimated glomerular filtration rate (eGFR) was calculated using the formula [eGFR (ml/ $\left.\min / 1.73 \mathrm{~m}^{2}\right)(7)=194 \times \mathrm{Cr}^{-1.094} \times$ age $^{-0.287}$ (female: $\mathrm{x}$ 0.739)] as established by the Japanese Society of Nephrology. Patients showing an eGFR of $<60 \mathrm{ml} / \mathrm{min} / 1.73 \mathrm{~m}^{2}$ or a urinary albumin level of $\geq 30 \mathrm{mg} / \mathrm{g} \cdot \mathrm{Cr}$ before the start of irbesartan administration were regarded as having nephropathy. The study objective and method were fully explained to the subjects, and written informed consent was obtained.

Statistical analysis. Various parameters were expressed as the mean \pm standard deviation, excluding those with notes. To compare the mean 24-h blood pressure and pre-/post-treatment values, the Student's t-test was employed. When comparing data on repetitive blood pressure/pulse measurements to the pre-treatment values, Bonferroni's correction was performed, considering test multiplicity. $\mathrm{P}<0.0167(\approx 0.05 \div 3)$ was regarded as significant. Concerning other items, $\mathrm{P}<0.05$ was regarded as significant. With respect to the urinary albumin level, significance was tested after routine logarithmic transformation, as a log-normal distribution was assumed.

Patient backgrounds. This study was completed in 30 of the 32 subjects. Two patients did not consult the outpatient clinic as scheduled, dropping out of the study. There was no discontinuation related to adverse reactions. The backgrounds of the 30 patients are shown in Table I. They consisted of 11 males and 19 females with a mean age of 61.3 years. The mean systolic and diastolic blood pressures determined at the outpatient clinic were $169.9 \pm 18.5$ and $92.4 \pm 11.8 \mathrm{mmHg}$, respectively.

The mean urinary albumin and serum creatinine levels were $60.8 \pm 155.5 \mathrm{mg} / \mathrm{g} \cdot \mathrm{Cr}$ and $0.671 \pm 0.173 \mathrm{mg} / \mathrm{dl}$, respectively. The eGFR was $81.2 \pm 18.8 \mathrm{ml} / \mathrm{min} / 1.73 \mathrm{~m}^{2}$. Of the 30 patients, 
Table I. Patient characteristics at baseline.

\begin{tabular}{lc}
\hline Demographics & \\
Male/female & $11 / 19$ \\
Age (years) & $61.3 \pm 13.3$ \\
Office blood pressure & \\
SBP $(\mathrm{mmHg})$ & $169.9 \pm 18.5$ \\
DBP $(\mathrm{mmHg})$ & $92.4 \pm 11.8$ \\
Renal parameters & \\
Serum creatinine $(\mathrm{mg} / \mathrm{dl})$ & $0.671 \pm 0.173$ \\
eGFR $\left(\mathrm{ml} / \mathrm{min} / 1.73 \mathrm{~m}^{2}\right)$ & $81.2 \pm 18.8$ \\
Urinary albumin $(\mu \mathrm{g} / \mathrm{g} \cdot \mathrm{Cr})$ & $60.8 \pm 155.5$
\end{tabular}

SBP, systolic blood pressure; DBP, diastolic blood pressure; eGFR, estimated glomerular filtration rate.

Table II. Patient distribution: baseline urinary albumin (U-Alb) and estimated glomerular filtration rate (eGFR).

\begin{tabular}{lrrrr}
\hline eGFR & $\geq 90$ & $60-90$ & $\leq 60$ & Total \\
\hline U-Alb & & & & \\
$\leq 30$ & 5 & 13 & 2 & 20 \\
$30-300$ & 2 & 6 & 1 & 9 \\
$\geq 300$ & - & 1 & - & 1 \\
Total (n) & 7 & 20 & 3 & 30 \\
\hline
\end{tabular}

10 showed abnormal urinary albumin levels (microalbuminuria 9; manifest albuminuria 1). In 3 patients, the eGFR was $<60 \mathrm{ml} / \mathrm{min} / 1.73 \mathrm{~m}^{2}$. The distribution of the urinary albumin

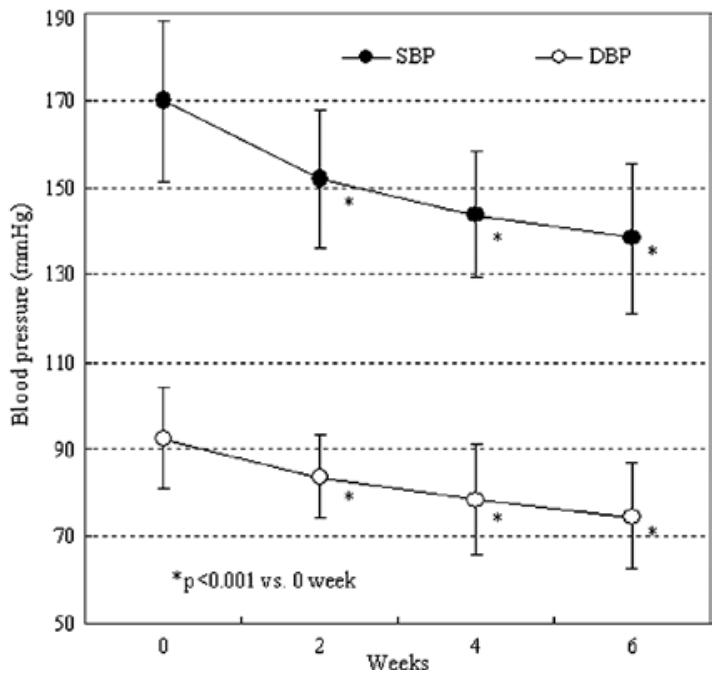

Figure 2. Office blood pressure.

level/eGFR-stratified patients is shown in Table II. A total of 12 patients had nephropathy, showing an eGFR of $<60 \mathrm{ml} /$ $\mathrm{min} / 1.73 \mathrm{~m}^{2}$ or a urinary albumin level of $\geq 30 \mathrm{mg} / \mathrm{g} \cdot \mathrm{Cr}$.

\section{Results}

Both the systolic and diastolic office blood pressures were significantly decreased after 2 weeks of irbesartan administration $(\mathrm{P}<0.001)$. After 6 weeks of administration, the values were 138.8 and $74.4 \mathrm{mmHg}$, respectively (Fig. 2). As shown in Fig. 3, 24-h blood pressure control was achieved by administration of irbesartan. The mean 24-h systolic and diastolic blood pressures significantly decreased from $162.7 \pm 17.7$ and $85.5 \pm 5.8$ to $131.9 \pm 9.0$ and $75.5 \pm 7.5 \mathrm{mmHg}$, respectively. Both the nocturnal and daytime blood pressures significantly

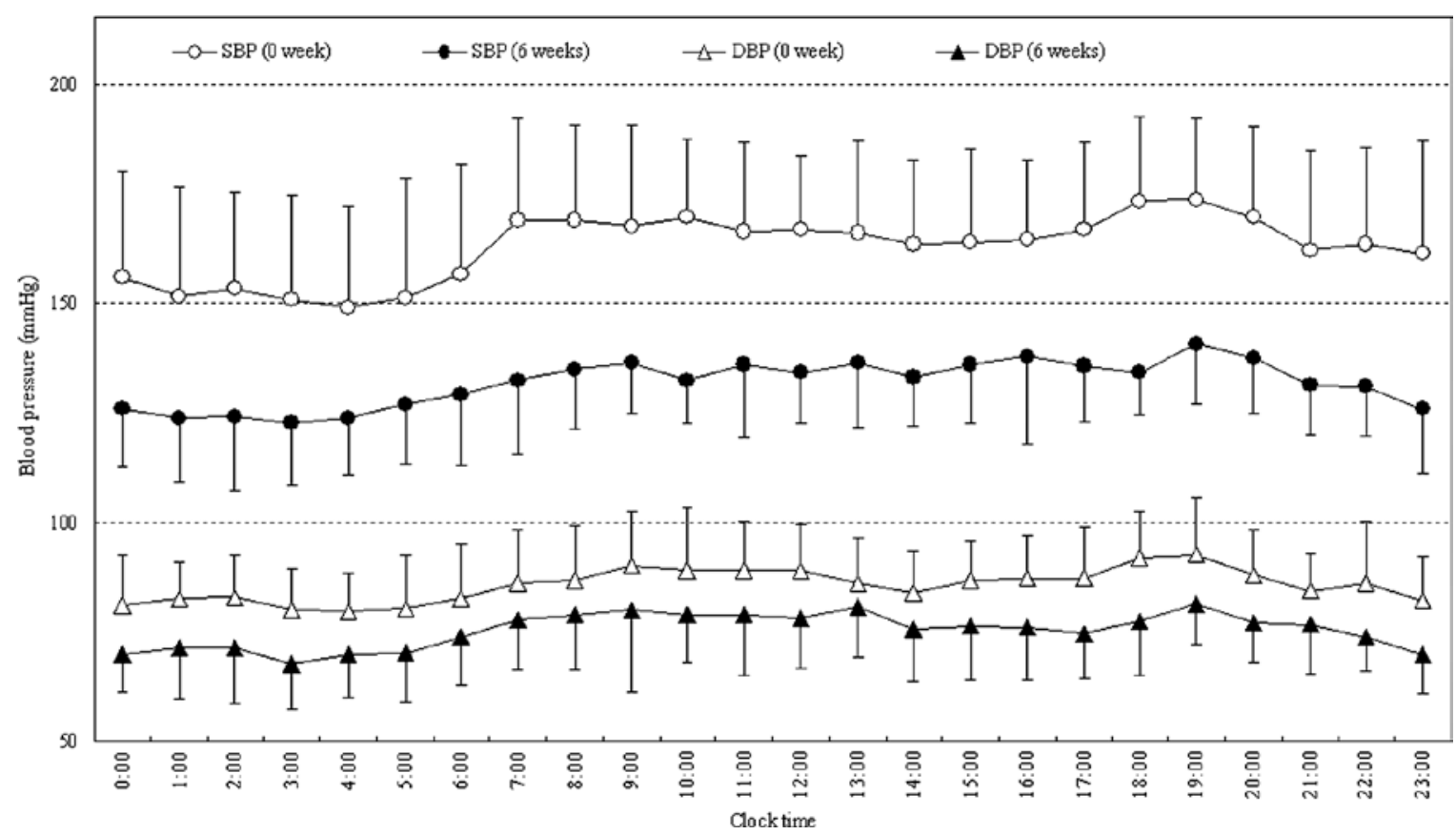

Figure 3. Effect of irbesartan on 24-h ambulatory blood pressure. 

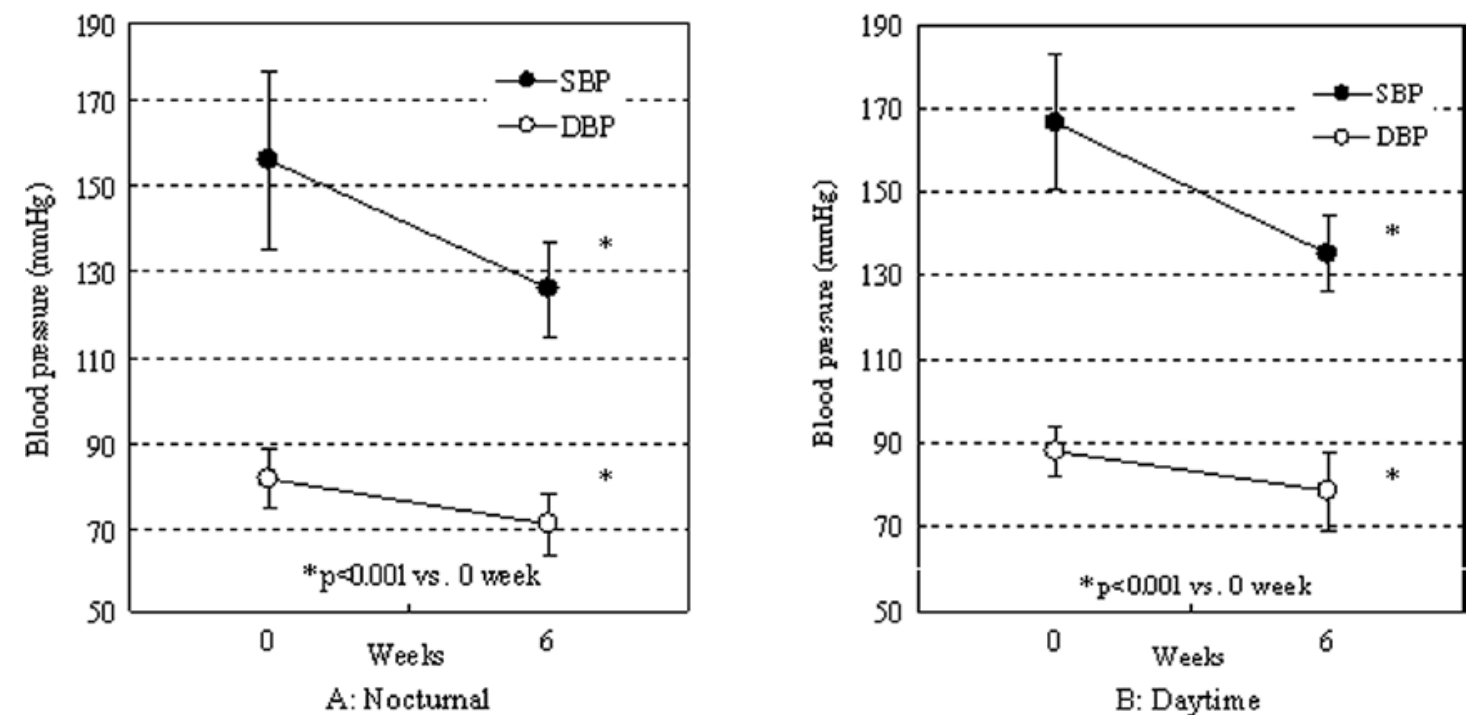

Figure 4. Effect of irbesartan on nocturnal/daytime blood pressure.

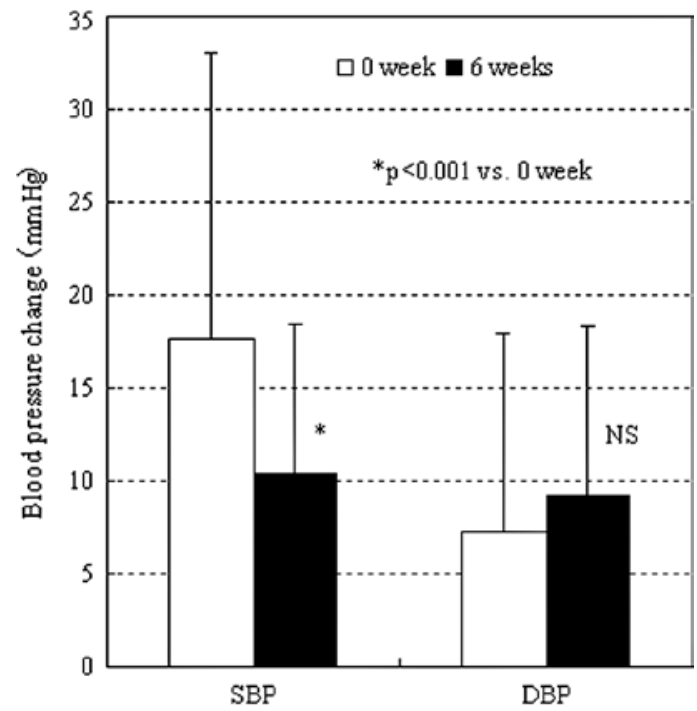

Figure 5. Effect of irbesartan on morning surge.

decreased (Fig. 4A and B). The rate of decrease was similar between the nocturnal and daytime blood pressures (systolic: $29.8 \pm 20.1$ vs. $31.5 \pm 19.4 \mathrm{mmHg}$; diastolic: $10.8 \pm 6.7$ vs. $9.7 \pm 6.8 \mathrm{mmHg}$, respectively).

The rates of increase in the systolic blood pressure early in the morning before and 6 weeks after the start of administration were $17.6 \pm 15.5$ and $10.5 \pm 10.8 \mathrm{mmHg}$, respectively, showing a significant difference (Fig. 5) $(\mathrm{P}<0.05)$. There was no significant difference in the rate of change in the diastolic blood pressure.

We compared changes in blood pressure-associated parameters between the 12 patients with nephropathy and the other 18 patients. There were no marked differences. For influence on kidney-associated parameters, in 10 patients with abnormal urinary albumin levels before irbesartan administration, the mean urinary albumin level was significantly decreased from $152.9 \pm 252.3$ (before administration) to $45.9 \pm 38.6 \mathrm{mg} / \mathrm{g} \cdot \mathrm{Cr}$ after 6 weeks of administration $(\mathrm{P}<0.05)$.

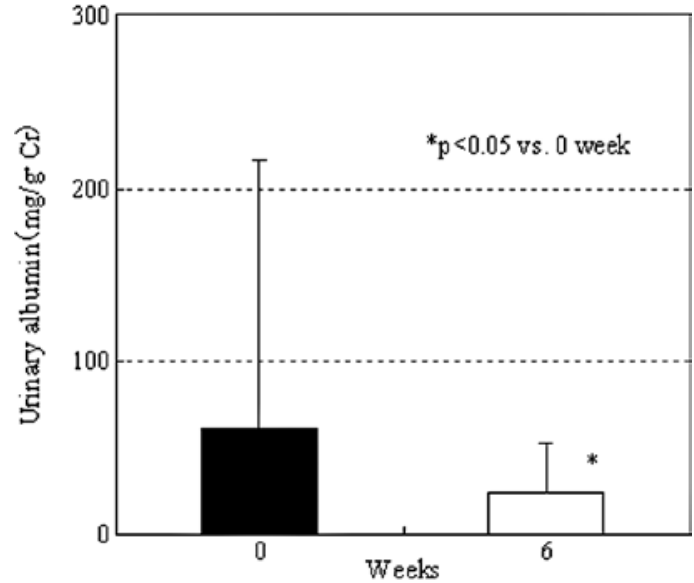

Figure 6. Effect of irbesartan on urinary albumin excretion.

In 5 patients, the urinary albumin levels were normalized. In 20 patients, in whom the pre-treatment urinary albumin levels were within the normal range, there was no significant change (from $14.8 \pm 6.8$ to $13.8 \pm 11.5 \mathrm{mg} / \mathrm{g} \cdot \mathrm{Cr}$ ) (Fig. 6). However, in 1 patient the urinary albumin level increased from 27.2 to $55.9 \mathrm{mg} / \mathrm{g} \cdot \mathrm{Cr}$, showing deterioration from the normal range to the microalbuminuria level. In this patient, subsequent examination confirmed a decrease, despite continuous therapy with irbesartan, suggesting a transient change. After 6 weeks of administration, there was a slight increase in the eGFR $\left(83.8 \pm 23.1 \mathrm{ml} / \mathrm{min} / 1.73 \mathrm{~m}^{2}\right)$ in comparison to that before irbesartan administration $\left(81.2 \pm 18.8 \mathrm{ml} / \mathrm{min} / 1.73 \mathrm{~m}^{2}\right)$, although the difference was not significant. There were no serious side effects requiring discontinuation of the test agent.

\section{Discussion}

In humans, the daily heart rate is approximately 100,000 beats. The blood pressure changes on every beat depending on the sympathetic nervous system and humoral factors. Recent studies have indicated that the non-office blood pres- 
sure markedly influences the prognosis, such as the onset of cardiovascular events $(8,9)$. Therefore, it may be important to evaluate not only office, but also daytime/nocturnal blood pressures during activities/sleep $(10,11)$.

The half-life of irbesartan at a clinical dose is long (10.2-15.4 h) (4). In addition, this agent exhibits stable, continuous, anti-hypertensive and renoprotective effects over $24 \mathrm{~h}(6,12,13)$. However, in Japan few studies have reported its efficacy. As evidence regarding irbesartan involves doses employed in other countries (150-300 mg/day) (3), the antihypertensive and renoprotective effects of this agent at doses approved in Japan, 50-200 mg/day, should be compared to those of other ARBs.

In this study, we examined 24-h blood pressure control using ABPM in Japanese patients with essential hypertension who were treated with irbesartan and evaluated its efficacy. This agent decreased both the nocturnal and daytime blood pressures and reduced the rate of change in the systolic blood pressure early in the morning, resulting in favorable blood pressure control. It also significantly decreased the urinary albumin level, suggesting that it exhibits renoprotective effects at doses approved in Japan.

According to Kario et al (14), blood pressure changes early in the morning, morning surge, may be an important factor influencing the prognosis of cardiovascular events. The approved doses differing between Japan and other countries remain controversial, considering the clinical efficacy. However, in this study, irbesartan at a standard dose $(100 \mathrm{mg} /$ day, once a day) employed in Japan reduced the daytime/ nocturnal blood pressures and morning surge, suggesting its potent effects as a long-acting anti-hypertensive agent.

A meta-analysis involving 36 international studies showed that the effects on 24-h blood pressure changes depended on the type of ARB (15). ARB selection in anti-hypertensive treatment may be important for blood pressure control. All ARBs approved in Japan, consisting of six components, are administered once a day. Although there are marked differences in the half-life and pharmacokinetics, few studies have compared 24-h blood pressure control among the ARBs. Further investigations are required.

\section{References}

1. Chonan K, Kikuya M, Araki T, Fujiwara T, Suzuki M, Michimata M, Hashimoto J, Ohkubo T, Hozawa A, Yamamoto N, Miyawaki Y, Matsubara M and Imai Y: Device for the selfmeasurement of blood pressure that can monitor blood pressure during sleep. Blood Press Monit 6: 203-205, 2001.
2. Ogihara T, Kikuchi K, Matsuoka H, et al: The Japanese Society of Hypertension Guidelines for the Management of Hypertension (JSH 2009). Hypertens Res 32: 3-107, 2009.

3. Croom KF and Plosker GL: Irbesartan: a review of its use in hypertension and diabetic nephropathy. Drugs 68: 1543-1569, 2008.

4. Marino MR, Langenbacher K, Ford NF and Uderman HD: Pharmacokinetics and pharmacodynamics of irbesartan in healthy subjects. J Clin Pharmacol 38: 246-255, 1998.

5. Cazaubon C, Gougat J, Bousquet F, Guiraudou P, Gayraud R, Lacour C, Roccon A, Galindo G, Barthelemy G, Gautret B, Bernhart C, Perreaut P, Breliere J, Fur GL and Nisato D: Pharmacological characterization of SR 47436, a new nonpeptide AT1 subtype angiotensin II receptor antagonist. J Pharmacol Exp Ther 265: 826-834, 1993.

6. Van den Meiracker AH, Admiraal PJ, Janssen JA, Kroodsma JM, de Ronde WA, Boomsma F, Sissmann J, Blankestijn PJ, Mulder PG, Man in't Veld AJ and Schalekamp MADH: Hemodynamic and biochemical effects of the AT1 receptor antagonist irbesartan in hypertension. Hypertension 25: 22-29, 1995.

7. Matsuo S, Imai E, Horio M, Yasuda Y, Tomita K, Nitta K, Yamagata K, Tomino $\mathrm{Y}$, Yokoyama $\mathrm{H}$ and Hishida A: Collaborators developing the Japanese equation for estimated GFR. Revised equations for estimated GFR from serum creatinine in Japan. Am J Kidney Dis 53: 932-935, 2009.

8. Bobrie G, Chatellier G, Genes N, Clerson P, Vaur L, Vaisse B, Menard J and Mallion JM: Cardiovascular prognosis of 'masked hypertension' detected by blood pressure self-measurement in elderly treated hypertensive patients. JAMA 291: 1342-1349, 2004.

9. Ohkubo T, Kikuya M, Metoki H, Asayama K, Obara T, Hashimoto J, Totsune K, Hoshi H, Satoh H and Imai Y: Prognosis of 'masked' hypertension and 'white-coat' hypertension detected by 24-h ambulatory blood pressure monitoring 10-year follow-up from the Ohasama study. J Am Coll Cardiol 46: 508-515, 2005.

10. Harada K, Karube Y, Saruhara H, Takeda K and Kuwajima I: Workplace hypertension is associated with obesity and family history of hypertension. Hypertens Res 29: 969-976, 2006.

11. Kario K, James GD, Marion R, Ahmed M and Pickering TG: The influence of work- and home-related stress on the levels and diurnal variation of ambulatory blood pressure and neurohumoral factors in employed women. Hypertens Res 25: 499-506, 2002.

12. Parving HH, Lehnert $\mathrm{H}$, Bröchner-Mortensen J, Gomis R, Andersen $\mathrm{S}$ and Arner $\mathrm{P}$ (Irbesartan in Patients with Type 2 Diabetes and Microalbuminuria Study Group): The effect of irbesartan on the development of diabetic nephropathy in patients with type 2 diabetes. N Engl J Med 345: 870-878, 2001.

13. Lewis EJ, Hunsicker LG, Clarke WR, Berl T, Pohl MA, Lewis JB, Ritz E, Atkins RC, Rohde R and Raz I (Collaborative Study Group): Renoprotective effect of the angiotensin-receptor antagonist irbesartan in patients with nephropathy due to type 2 diabetes. N Engl J Med 345: 851-860, 2001.

14. Kario K, Pickering TG, Umeda Y, Hoshide S, Hoshide Y, Morinari M, Murata M, Kuroda T, Schwartz JE and Shimada K: Morning surge in blood pressure as a predictor of silent and clinical cerebrovascular disease in elderly hypertensives: a prospective study. Circulation 107: 1401-1406, 2003.

15. Fabia MJ, Abdilla N, Oltra R, Fernandez C and Redon J: Antihypertensive activity of angiotensin II AT1 receptor antagonists: a systematic review of studies with $24 \mathrm{~h}$ ambulatory blood pressure monitoring. J Hypertens 25: 1327-1336, 2007. 